\title{
BLACK BIRCH ASTROMETRIC OBSERVATORY
}

\author{
D. Robinson, Dr. S. Dick, Dr. R. Stone, B. Loader \\ United States Naval Observatory \\ Washington DC \\ U.S.A
}

The seven inch transit circle near Blenheim, New Zealand is intended in conjunction with the six inch circle at Washington, to produce a fundamental catalogue and to re-observe the Southern Reference Stars.

The transit circle is designed to set and automatically acquire a star on input of its reference number. After the observation the data gathered is stored on disk. Subsequently following reduction it is stored on magnetic tape.

Photographs and diagrams showed the Black Birch site, the telescope, computer and clock system, image dissector and the setting circle with scanning microscopes. 